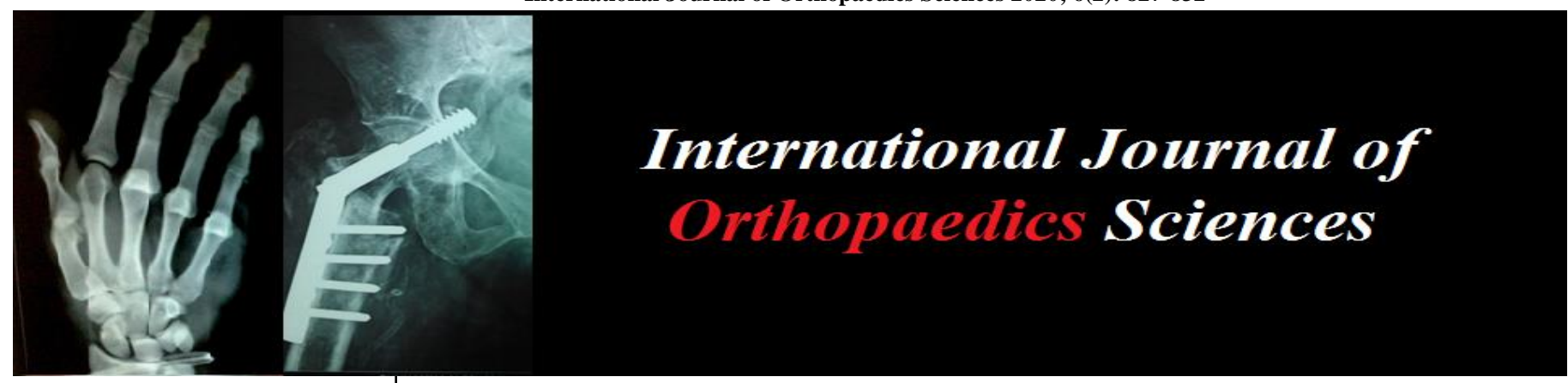

E-ISSN: 2395-1958

P-ISSN: 2706-6630

IJOS 2020; 6(2): 827-832

(C) 2020 IJOS

www.orthopaper.com

Received: 01-02-2020

Accepted: 03-03-2020

Dr. Vamshi Krishna Reddy Chilakamary

Asst Prof, Dept. of Orthopaedics, KIMS Narketpally, Nalgonda,

Telangana, India

Dr. Sadhan Palakuri

Senior Resident, Dept. of

Orthopaedics, KIMS

Narketpally, Nalgonda,

Telangana, India

Dr. Srinivas Yerramaneni Associate Professor, Dept. of Orthopaedics, KIMS

Narketpally, Nalgonda,

Telangana, India
Corresponding Author:

Dr. Vamshi Krishna Reddy Chilakamary

Asst Prof, Dept of Orthopaedics, KIMS Narketpally, Nalgonda,

Telangana, India

\section{A prospective study to assess the functional and radiological outcome of subtrochanteric femoral fractures using 95 degree dynamic condylar screw}

\author{
Dr. Vamshi Krishna Reddy Chilakamary, Dr. Sadhan Palakuri and \\ Dr. Srinivas Yerramaneni
}

DOI: https://doi.org/10.22271/ortho.2020.v6.i2n.2146

\begin{abstract}
Introduction: The absolute majority of the trochanteric and subtrochanteric hip fracture patients are fragile patients with a tendency to fall and an increased risk of major morbidity and mortality. It is important to provide adequate management to these patients and the treatment of choice is normally surgical with internal fixation. The surgical options for these fractures commonly include plating with sliding hip screw or intramedullary nailing, with nailing today being the predominant procedure in many parts of the world. The rationale of operative treatment of subtrochanteric fracture should be to obtain adequate reduction, achieve stability and to provide adequate fracture fixation. The final aim of treatment remains early union in anatomical position with early, active, pain free mobilization and the patient returning to his routine activities at the earliest. During the last century several implants have been tried to treat these fractures surgically. The very fact that several implants have been tried proves that no one implant is found suitable in all cases. Extramedullary implants like Dynamic Hip Screw and Dynamic Condylar Screw were used to fix the fracture. Dynamic Hip Screw often fails to prevent lateral drift of the proximal fragment which leads to implant failure. Dynamic Condylar screw provides better stability because of the fixation of proximal fragment with an additional screw in the calcar region, it also facilitates vertical load transmission.The dynamic condylar screw (an extra medullary implant) which exerts vertical forces on weight bearing is a better option as it provides strong fixation in the cancellous bone of the neck and head with considerable rotational stability.

Material and Methods: We evaluated the functional outcome of subtrochanteric fractures treated with Dynamic Condylar Screw in 12 patients from October 2015 to September 2017 at Kamineni Institute of Medical Sciences in a prospective study.

Results: Mean age of the patients in the was 58.9 years. Mode of injury - 75\% (9) patients sustained injury due to road traffic accidents and $25 \%$ (3) patients sustained injury due to fall.66.67\% (8) patients were males and $33.33 \%$ (4) patients were females.

There was almost an equal distribution in regards to side of injury. Average radiological union duration was 17 weeks. Duration of follow up was 6months.8.33\% (1) patient had superficial infection.8.33\% (1) patient had lag screw cut through for which secondary procedure was done. Modified Harries Hip score at the end of the follow up was $58.34 \%$ (7) patients with excellent score, $33.33 \%$ (4) patients with good score and $8.33 \%$ (1) patient had poor score.

Conclusion: Subtrochanteric fractures of the Femur pose a challenge to the surgeon in the view of its peculiarities of anatomy, biomechanical forces acting across the fracture site and technical difficulties of reduction and application of a suitable implant. Many implants both Intramedullary and Extramedullary have been tried by various surgeons in different time periods with varying results. In this study Dynamic Condylar Screw and plate for selected patients and results were compared with other available references. DCS is a good implant when applied in a correct manner and yields good results in terms of fracture healing with minimal complications.
\end{abstract}

Keywords: Subtrochanteric fracture, dynamic condylar screw, proximal femur fractures, harris hip score, prospective study

\section{Introduction}

The absolute majority of the trochanteric and subtrochanteric hip fracture patients are fragile patients with a tendency to fall and an increased risk of major morbidity and mortality ${ }^{[1-4]}$. It is important to provide adequate management to these patients and the treatment of choice is 
normally surgical with internal fixation. The surgical options for these fractures commonly include plating with sliding hip screw or intramedullary nailing, with nailing today being the predominant procedure in many parts of the world ${ }^{[5,6]}$

Subtrochanteric fractures of the femur present considerable challenge in their management. Despite improvement in patients care and operative technique, they account for significant amount of morbidity and health care expenditure and hence have an important economic and social impact. In the twenty first century, there is an ever increasing use of high speed transport, there by increasing number of accidents leading to increase in the fracture incidences. Subtrochanteric fractures, a variant of peritrochanteric fractures / proximal femoral fractures have been reported to constitute $10-30 \%$ of proximal femoral fractures. They have bipolar age distribution with different mechanisms of injury in each group. In elderly the etiology of the subtrochanteric fractures is the combination of increased bone fragility of the subtrochanteric area of the femur associated with decreased muscle tone secondary to the ageing process. The increasing bone fragility results from osteoporosis secondary to lack of adequate ambulation, antigravity activities, decreased osteoprotective hormone levels, decreased intake of calcium and vitamin D.

The combination of increased fragility of the bone and a traumatic event may result in either a direct impact or generation of a force transmitted through the leg to the subtrochanteric area. When such forces are greater than the strength of the bone in the subtrochanteric area, a fracture occurs. In the young adults fractures occur due to high velocity trauma. Constant in their occurrence and being difficult to manage, they frequently cause serious and disastrous consequences. Operative treatment remains mainstay of management of this fracture. The difficulties that these fractures pose in their management are multifactorial ranging from anatomical peculiarities and muscular forces across the fracture site, high stress concentration in the subtrochanteric area, varying degree of comminution, making maintenance of reduction and fixation difficult,, Increased duration and magnitude of surgery, increased blood loss and higher incidence of post-operative complications ,uncertainty in surgical technique because of complexity of fracture configuration pose a challenge to the surgeon, slow healing time because of predominance of cortical bone, long period of immobilization, increasing morbidity effecting patient, socially, economically and psychologically. The rationale of operative treatment of subtrochanteric fracture should be to obtain adequate reduction, achieve stability and to provide adequate fracture fixation. The final aim of treatment remains early union in anatomical position with early, active, pain free mobilization and the patient returning to his routine activities at the earliest. During the last century several implants have been tried to treat these fractures surgically. The very fact that several implants have been tried proves that no one implant is found suitable in all cases. Extramedullary implants like Dynamic Hip Screw and Dynamic Condylar Screw were used to fix the fracture. Dynamic Hip Screw often fails to prevent lateral drift of the proximal fragment which leads to implant failure. Dynamic Condylar screw provides better stability because of the fixation of proximal fragment with an additional screw in the calcar region, it also facilitates vertical load transmission. The dynamic condylar screw (an extra medullary implant) which exerts vertical forces on weight bearing is a better optionas it provides strong fixation in the cancellous bone of the neck and head with considerable rotational stability. In this prospective study we evaluated functional and radiological results of subtrochanteric femoral fractures treated with Dynamic Condylar Screw.

\section{Material and Methods}

We evaluated the functional outcome of subtrochanteric fractures treated with

Dynamic Condylar Screw in 12 patients from October 2015 to September 2017 at

Kamineni Institute of Medical Sciences.

\section{Inclusion criteria}

- Patients between age group 20 - 75 years

- All types of subtrochanteric femoral fractures based on Seinsheimers classification

\section{Exclusion criteria}

- Skeletally immature patients (19years and below)

- Patients with pathological fractures

- Patients with compound fractures

- Patients with associated neuromuscular complications

- Patients with multiple fractures

Each patient with injury around Hip joint was reviewed in emergency department and examined thoroughly for associated injuries. Antero-posterior and lateral radiographs of affected hip were taken to assess the fracture pattern according to SeinsheimerClassification.

All patients were admitted and temporary immobilization was given in form of proximal tibialskeletal traction by Steinmann-pin under local anesthesia and limb was placed on a Bohler'ssplint in 45 degree of abduction at hip, with weight equal to $10 \%$ of body weight. Necessary investigations for surgical fitness were conducted. Pre-operatively, caputcollum-diaphyseal angle (CCD angle-projection of the angle between diaphysis and the femoral neck) was measured from radiographs of the opposite limb.

Procedure-

After giving spinal or epidural anesthesia, patient was placed in supine positionon a traction table. All patients were given preoperative intravenous antibiotic.we used lateral approach after attempting closed reduction. A guide pin was placed on the anterior surface of the femoral neck to determine the anteversion. Another guide pin was inserted across the femoral neck, with due consideration paid to the degree of anteversion and the fixed angle of the implant, such that the tipof the guide pin was seated $2 \mathrm{~cm}$ short of the articular surface in the lower half of the femoral head. Reaming and tapping were done over the second guide pin. An appropriate length condylar screw was fixed in to the subchondral bone. A suitable side plate was applied. At least four screws engaging 8 cortices were applied distal to the main fracture. Minor fragments were lagged in an attempt to restore medial bone support. Bone grafting was carried out in cases of severe posteromedial comminution in Type A and B fractures where it was not possible to hold the posteromedial area with screws in spite of the anatomical alignment. The focus was on obtaining the length, mechanical and rotational alignments. Correct alignment and rotation were checked intraoperatively using C-arm guidance. The incision was closed overa negative suction drain. Postoperatively, intra-venous antibiotics were given to all patients for 6 days followed by oral antibiotics for another 5 days. Drain was removed after 48 hours. Patients were taught static quadriceps exercises, knee bending exercises and high sitting exercises as tolerated in the postoperative period. According to stability of fixation, 
postoperative non weight bearing or partial weight bearing crutch walking was started. First follow-up was after 4 weeks and thereafter patient was reviewed at every 4 weeks. Patient was examined clinically (operated site, range of motion, deformity, shortening etc) and radiographically (status of union, position of implant etc) as per the predefined parameters. The results were rated on the basis of Modified Harris Hip Score at 4, 6, 12 and 24 weeks.

\section{Parts of Dynamic Condylar Screw}
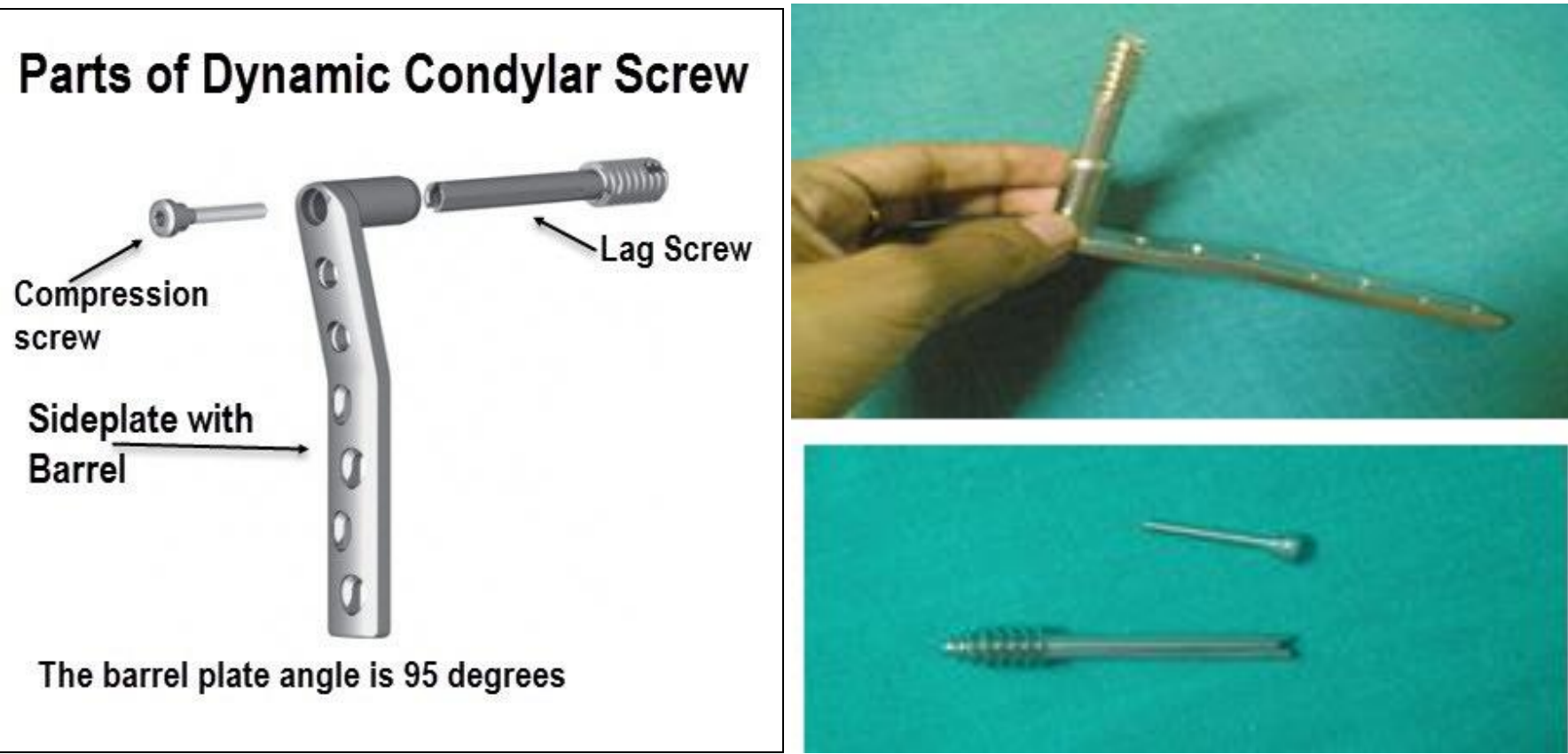

Parts of Dynamic Condylar Screw

\section{Postoperative Rehabilitation}

On post op day 1 Isometric quadriceps and knee flexion exercises with the hip in neutral rotation are started as soon as postoperative pain is tolerable. Hip flexion exercises are permitted after 1 week (usually by this time, the postoperative pain subsides and the patient is comfortable with actively assisted motion at the hip), along with non-weight-bearing ambulation with axillary crutches. Sutures are removed at 12 days. Partial weight bearing is started as per progress of fracture union on follow-up radiographs (usually 4-6 weeks) with gradual progression to full weight bearing. Followup is done at 4, 6, 12, 24 weeks. Final assesment was done by modified Harris Hip Score.

\section{Results and Discussion}

The following are the observations of all the 12 patients with subtrochanteric fracture management with 95 deg Dynamic condylar screw.

With respect to age and sex distribution of 12 patients included in the study following are the observations

Table 1: Age Distribution in This Study $(n=12)$

\begin{tabular}{|c|c|c|}
\hline Age & Number of Patients & Percentage \\
\hline $31-40$ & 3 & 25 \\
\hline $41-50$ & 1 & 8.33 \\
\hline $51-60$ & 4 & 33.37 \\
\hline $61-70$ & 3 & 25 \\
\hline$>70$ & 1 & 8.33 \\
\hline Total & 12 & 100 \\
\hline
\end{tabular}

The mean age in our study was 58.9 years. The mean age in Rohilla $\mathrm{R}$ et al. ${ }^{[7]}$ study was 44 . The mean age in Sunil V Patil et al ${ }^{[8]}$ was 44.5 years. The mean age in Syed Arsalan Haider Bukhari ${ }^{[9]}$ was 44 years. This shows that the majority of the injuries occur in the age group belonging to 4 th and 5 th decade of life.
In this series 8 patients were male and 4 were female. This shows preponderance of males over females. In our study the right side was affected in 7 cases $(58 \%)$ and the left side was involved in 5 cases $(42 \%)$. Out of 12 cases 9 cases gave history of road traffic accidents, 3 cases gave history of slip and fall. In our series road traffic accidents contributed to $75 \%$ of the injuries.

The following are the type of fractures in the study group using Seinshemer classification

Table 2: Evaluation of Type of Fracture in This Study $(\mathrm{N}=12)$

\begin{tabular}{|c|c|c|}
\hline Seinshemer & Number Of Patients & Percentage \\
\hline Type 1 & NIL & - \\
\hline Type 2A & NIL & - \\
\hline Type 2B & 3 & 25 \\
\hline Type 2C & 1 & 8.33 \\
\hline Type 3A & 5 & 41.67 \\
\hline Type 3B & 2 & 16.67 \\
\hline Type 4 & 1 & 8.33 \\
\hline Type 5 & NIL & - \\
\hline Total & 12 & 100 \\
\hline
\end{tabular}

In the study done by Sharma V et al. ${ }^{[10]}$ patients had type 3, 15 patients had type 4 and 22 patients had type 5 . In the study done by Liem MS et al. ${ }^{[11]} 1$ patient had type 2 fracture, 4 patients had type 3 fractures and 1 patient had type 4 fracture. In our study majority of the injuries were Seinsheimer type 3 due to high velocity injuries that occur in road traffic accident.

Majority of the patients $(66.67 \%)$ in this study at the end of 24 weeks of follow up had either no pain or slight pain which did not effect their activities. Only one patient $(8.33 \%)$ had moderate pain. $25 \%$ (3) patients had slight pain which was relieved with analgesics. In the current study 8 patients had no limp and 3 patients had slight limp that did not effect their activities. 1 patient $(8.33 \%)$ had severe limp which was 
mainly due to shortening. In our study $66.67 \%$ (8) patients did not require any support for walking and 25\% (3) of patients can walk with cane or stick for long walks. Only 1 patient was walking with stick most of the time. In our study at the end of 24 weeks followup 75\% (9) patients can walk unlimited distance and $25 \%$ (3) of patients can walk for six blocks (one block is 200metres in length). In this series, $75 \%$ (9) of patients could climb stairs normally without use of railing but $16.67 \%$ (2) required the support of railing. One patient was unable to climb the stairs. This difficulty was commonly seen in geriatric age group patients. Squatting was possible in $75 \%$ (9) with ease an with difficulty $16.67 \%$ (2). 1 patient was not able to squat. The difficulty in squatting was primarily seen in old age patients with osteoarthritis. In our study $83.33 \%$ (10) patients can comfortably sit in ordinary chair for one hour. $8.33 \%$ (1) patient can sit comfortably in a high chair for half an hour and $8.33 \%$ (1) patient unable to sit comfortably in any chair. In our study $100 \%$ Patients no significant deformities were found. In our study, $75 \%$ cases range of motion is between $211-300$ degrees, $16.67 \%$ cases range of motion is 161-210 degrees and only one patient with range of motion. Modified Harris Hip Score in the study were as follows-

Table 3: Evaluation of Modified Hip Score in This Study ( $\mathrm{n}=12$ )

\begin{tabular}{|c|c|c|c|}
\hline Grade & Score & Number of Patients & Percentage \\
\hline Excellent & $>90$ & 7 & 58.33 \\
\hline Good & $80-90$ & 4 & 33.34 \\
\hline Fair & $70-79$ & - & - \\
\hline Poor & $<70$ & 1 & 8.33 \\
\hline Total & & 12 & 100 \\
\hline
\end{tabular}

In this series all the $58.33 \%$ (7) of patients had Excellent results, 33.34\% (4) had good results and $8.33 \%$ (1) patient had poor result. In the study done by Syed Arsalan Haider Bukhari et al ${ }^{[9]}$. Functional outcome was excellent in 21 patients, good in 7 patients and poor in 1 patient. In the study done by Rohilla $\mathrm{R}$ et al ${ }^{[7]}$ functional outcome was excellent in 12 patients, good in 31 patients. In our study all the $58.33 \%$ (7) of patients had Excellent results, 33.34\% (4) had good results and $8.33 \%(1)$ patient had poor result

Table 4: Comparison of Functional Outcome by Modified Harris Hip Score with Different Studies

\begin{tabular}{|c|c|c|c|c|c|}
\hline S. No. & Author of other studies & Poor & Fair & Good & Excellent \\
\hline 1 & $\begin{array}{c}\text { Syed Arsalan Haider Bukhari } \\
\text { et al. }{ }^{[9]}(\mathrm{n}=29)\end{array}$ & 1 & - & 7 & 21 \\
\hline 2 & Rohilla R et al. ${ }^{[7]}(\mathrm{n}=43)$ & - & - & 31 & 12 \\
\hline 3 & our study $(\mathrm{n}=12)$ & 1 & - & 4 & 7 \\
\hline
\end{tabular}

In our study $66.67 \%$ (8) patients had radiological union at 6 months, $25 \%$ (3) had at union 9months after the surgery, while $8.33 \%$ (1) had no radiological union even after 9months

Table 5: Evaluation of Radiological Union in This Study ( $\mathrm{n}=12)$

\begin{tabular}{|c|c|c|}
\hline Time of Union (In Months) & Number of Patients & Percentage \\
\hline 3months & NIL & - \\
\hline 6months & 8 & 66.67 \\
\hline 9months & 3 & 25 \\
\hline >9months & 1 & 8.33 \\
\hline total & 12 & 100 \\
\hline
\end{tabular}

In our study average time for radiological union was 17.1 weeks whereas in the study carried out by Sharma $\mathrm{V}$ et al. ${ }^{[1]}$ it was 17.56 weeks, in Rohilla R et al. ${ }^{[7]}$. It was 16 weeks, in Manzoor Ahmed Halwai et al. ${ }^{[12]}$. It was 19.97, in Sunil V Patil et al. ${ }^{[8]}$ was 16.5 weeks and in Syed Arsalan Haider Bukhari ${ }^{[9]}$ it was 16 weeks. The results are almost consistent in the studies. This attributes to the biomechanical property of the implant as well as the fixation of fracture. In the present series, $8.33 \%$ (1) of cases had wound infection (superficial infection and no deep infections were recorded) for which wound debridement was done. Following table shows the various complications occurred in different studies in comparision to present study.

Table 5: Various Complications in Different Studies

\begin{tabular}{|c|c|c|c|c|c|c|c|c|}
\hline $\begin{array}{c}\text { S. } \\
\text { No. }\end{array}$ & $\begin{array}{c}\text { Author of other } \\
\text { studies }\end{array}$ & infection & $\begin{array}{c}\text { implant } \\
\text { failure }\end{array}$ & deformity & $\begin{array}{l}\text { limb length } \\
\text { discrepancy }\end{array}$ & $\begin{array}{l}\text { secondary } \\
\text { procedure }\end{array}$ & $\begin{array}{c}\text { non- } \\
\text { union }\end{array}$ & malunion \\
\hline 1 & Liem MS $[11]$ & none & 3 & 8 & none & 2 & none & none \\
\hline 2 & Sharma V [10] & 2 & none & 4 & 3 & none & none & none \\
\hline 3 & Rohilla R [7] & 1 & none & 2 & 7 & none & none & 1 \\
\hline 7 & our study & 1 & 1 & none & & 1 & 1 & none \\
\hline
\end{tabular}

In the study done by Syed Arsalan Haider Bukhari et al. ${ }^{[9]}$, Non-union was seen in one patient $(3.4 \%)(\mathrm{F}=1)$ whereas one patient $(3.4 \%)(\mathrm{M}=1)$ displayed atrophic-union (complex comminution pattern Evan's type I e). In the study done by Rohilla R [19] Seven patients had a mean limb length discrepancy of 1.5 (range, 1-2) $\mathrm{cm}$ (5 shortening, 2 lengthening). Acceptable alignment (<10degree varus/valgus and rotation) was achieved in all but 2 patients.

\section{Annexure-1}

Case-1

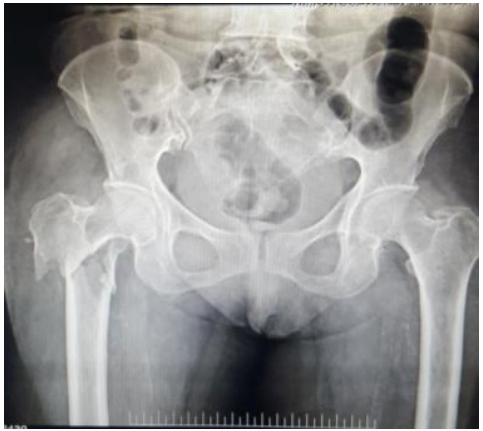

At Presentation

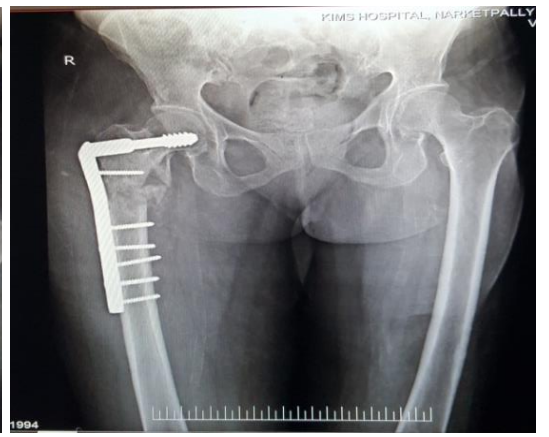

6wks Post Op 


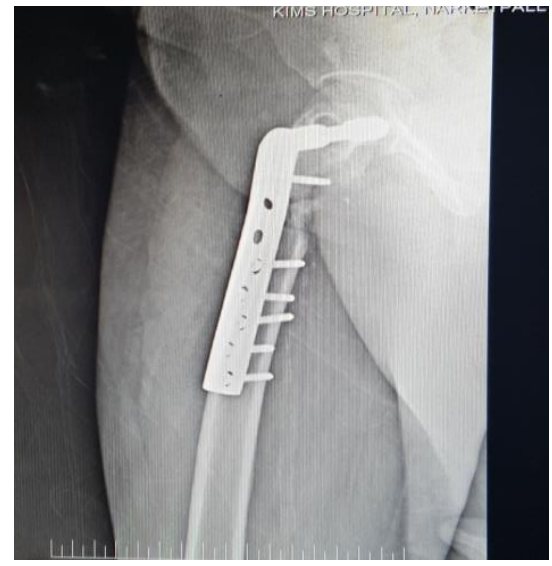

Union Progression at $3 \mathrm{Rd}$ Month

\section{Case-2}

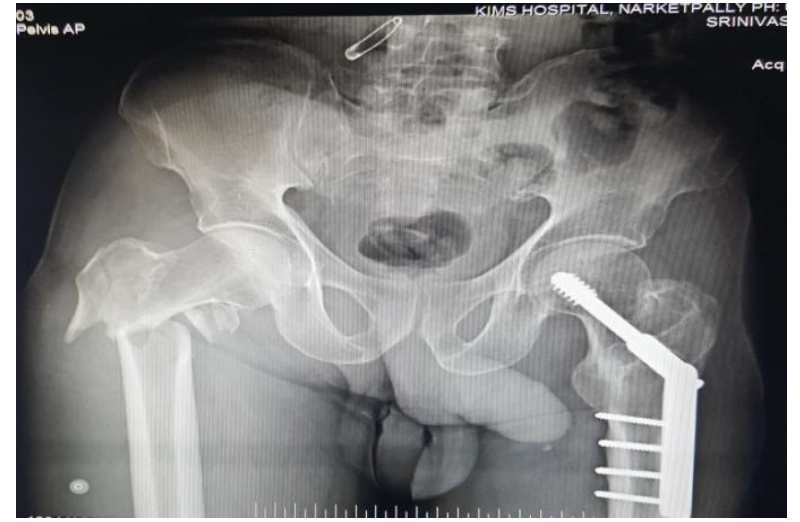

At Presentation

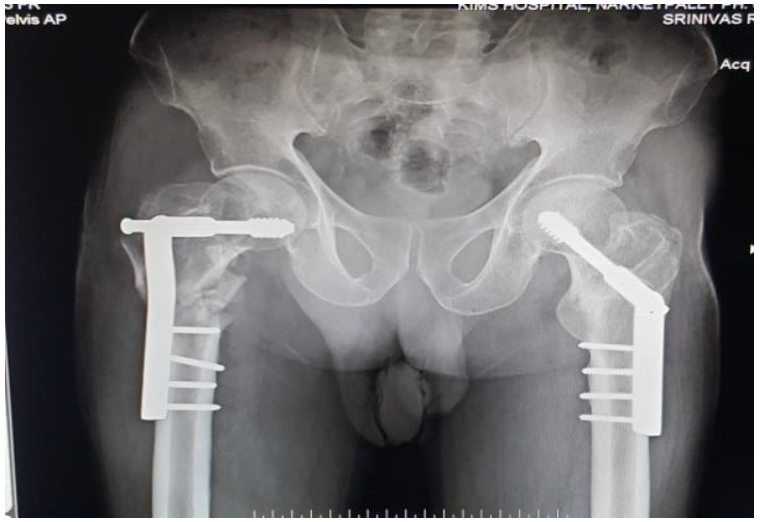

At 6 WKS Follow Up

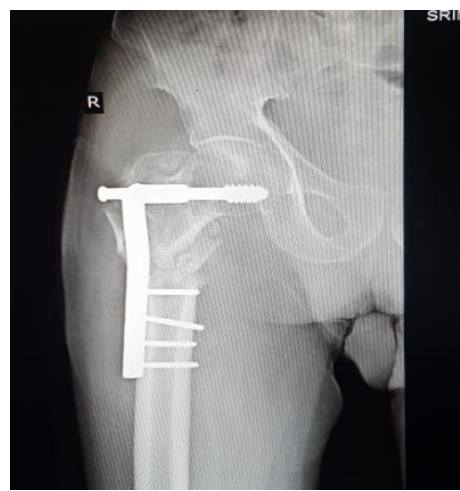

Union Progression AT 3rd Month

\section{Conclusion}

Many studies have shown that surgical management still leads to the best outcomes in patients with hip fractures ${ }^{[13,14]}$, with some studies showing non-inferiority of nonsurgical management as compared to surgery in low-grade fractures ${ }^{[15,16]}$. At our center, while surgery remains the mainstay of treatment for these fractures. Subtrochanteric fractures of the Femur pose a challenge to the surgeon in the view of its peculiarities of anatomy, biomechanical forces acting across the fracture site and technical difficulties of reduction and application of a suitable implant. Many implants both Intramedullary and Extramedullary have been tried by various surgeons in different time periods with varying results. In this study Dynamic Condylar Screw and plate for selected patients and results were compared with other available references. DCS is a good implant when applied in a correct manner and yields good results in terms of fracture healing with minimal complications. Further studies should be done comparing each type of subtrochanteric fracture with specific implant for radiological union and functional outcome.

\section{References}

1. Brunner LC, Eshilian-Oates L, Kuo TY. Hip fractures in adults. Am Fam Physician. 2003; 67(3):537-542.

2. Endo Y, Aharonoff GB, Zuckerman JD, Egol KA, Koval KJ. Gender differences in patients with hip fracture: a greater risk of morbidity and mortality in men. J Orthop Trauma. 2005; 19(1):29-35. doi: 10.1097/00005131200501000-00006.

3. Hagino H, Endo N, Harada A, Iwamoto J, Mashiba T, Mori S et al. Survey of hip fractures in Japan: recent trends in prevalence and treatment. J Orthop Sci. 2017; 22(5):909-914. doi: 10.1016/j.jos.2017.06.003. 
4. Matsuo M, Yamagami T, Higuchi A. Impact of age on postoperative complication rates among elderly patients with hip fracture: a retrospective matched study. J Anesth. 2018; 32(3):452-456. doi: 10.1007/s00540-0182494-8.

5. Anglen JO, Weinstein JN. Nail or plate fixation of intertrochanteric hip fractures: changing pattern of practice. A review of the American Board of Orthopaedic Surgery Database. J Bone Joint Surg Am. 2008; 90(4):700-707. doi: 10.2106/JBJS.G.00517.

6. Matre K, Havelin LI, Gjertsen JE, Vinje T, Espehaug B, Fevang JM. Sliding hip screw versus IM nail in reverse oblique trochanteric and subtrochanteric fractures. A study of 2716 patients in the Norwegian hip fracture register. Injury. 2013; 44(6):735-742. doi: 10.1016/j.injury.2012.12.010.

7. Rohilla R, Singh R, Magu NK, Siwach RC, Sangwan SS. Journal of Orthopaedic Surgery. 2008; 16(2):150-5.

8. Sunil V. Patil and Sangram Rajale. Subtrochanteric femoral fractures treated with dynamic condylar screw. Arch. Appl. Sci. Res. 2014; 6(3):94-101.

9. Syed Arsalan Haider Bukhari, Asif Asghar. Journal of Surgery Pakistan (International) 2011; 16(4):149-152.

10. Sharma V, Sharma S, Sharma S, Singh N, Dang H. Management Of Subtrochanteric Femoral Fractures By Dynamic Condylar Screw (DCS). The Internet Journal of Orthopedic Surgery. 2008, 11(2).

11. Liem MS, Lam HW, Yiu HW, Ngai WK. Hong Kong J Orthop Surg. 2006; 10(1):14-21.

12. Manzoor AH, Shabir AD, Mohammed IW, Mohammed FB, Bashir AM, Murtaza FA, Imtiyaz HD. The dynamic condylar screw in the management of subtrochanteric fractures: does judicious use of biological fixation enhance overall results? Strat Trauma Limb Reconstruction. 2007; 2:77-81.

13. Parker MJ, Handoll HH, Bhargara A. Conservative versus operative treatment for hip fractures. Cochrane Database Syst Rev. 2000; 4:CD000337.

14. Handoll HH, Parker MJ. Conservative versus operative treatment for hip fractures in adults. Cochrane Database Syst Rev. 2008; 3:CD000337.

15. Kawaji H, Uematsu T, Oba R. Conservative treatment for fracture of the proximal femur with complications. J Nippon Med Sch. 2016; 83(1):2-5.

16. Buord JM, Flecher X, Parratte S. Garden I femoral neck fractures in patients 65 years old and older: is conservative functional treatment a viable option? Orthop Traumatol Surg Res. 2010; 96(3):228-234. 